\title{
ESCAPE FROM DEXAMETHASONE SUPPRESSION: POSSIBLE ROLE OF AN IMPAIRED INHIBITORY OPIOI MECHANISM
}

\author{
Athanasios P. Zis, Roger F. Haskett, A. Ariav Albala, \\ and Bernard J. Carroll \\ Department of Psychiatry, University of Michigan \\ Ann Arbor, Michigan 48109
}

(Final fiom, June 1983)

\begin{abstract}
Zis, Athanasios P., Roger F. Haskett, A. Ariav Albala, Bernard J. Carroll: Escape from Dexamethasone Suppression: Possible Role of an Impaired Inhibitory Opioid Mechanism. Prog. Neuropsychopharmacol, and Biol. Psychiat, 1983, $Z$ (4-6):563-568.

1. Several lines of evidence indicate that the activity of the hypothalamus-pituitaryadrenal (HPA) axis in depression is disinhibited.

2. Escape from dexamethasone suppression, although not limited to is more feequent in patients with endogenous depression compared to nomals or patients with other psychiatric diagnoses.

3. Norepinephrine, serotonin and acetylcholine have been implicated in the pathophysiology of this neuroendocrine abnomality.

4. Morphine, $5 \mathrm{mg}$ intravenously, suppressed cortisol secretion in healthy volunteers ( $\mathrm{n}=4$ ) and the majority of 32 psychiatric inpatients.

5. However, patients wi th endogenous depression and abnormal dexamethasone suppression test results show early resumption (escape) of cortisol secretion following the initial suppression induced by morphine.

6. It is concluded that the pathophysiology of this neuroendocrine abnormality is not limited to classical neurotransmittef-HPA axis interaction but that it also involves opioid inhibitory mechanisms.
\end{abstract}

Keywords: dexamethasone, cortisol, depression, morphine

\section{Introduction}

Several lines of evidence implicate disinhibited activity of the hypothalamus-pituitaryadrenal (HPA) axis in the pathophysiology of depression (Sachar et al., 1973; Carroll et al., 1976a; Carroll et al., 1976b). Considerable support for this thesis has been derived from studies of the effects of dexamethasone on plasma cortisol; cortisol escape from dexamethasone, albeit not limited to, is characteristically more frequent in patients with endogenous depression than in normal subjects, non-endogenous depressives or in patients with other psychiatric diagnoses (Carroll et al., 1981, Coppell et al., 1983). Although several hypotheses have been suggested, the $s^{\prime}$ te and precise mechanism of this neuroendocrine dysregulation remains unclear. The purpose of this paper is to review hypotheses implicating classical neurotransmitter systems in this abnormallty and to present data indicating the involvement of impaired opioid inhibitory mechanisms. In doing so we will limit our discussion to studies pertaining to depression; for a general discussion of the neurotransmitter regulation of the HPA axis and the pathophysiology of this system in Cushing's disease the reader is referred elsewhere (Martin et al., 1977; Reichlin, 1981). 


\section{A. The Role of Classical Neurotransmitter Systems}

Catecholamines, the indoleamine serotonin and acetylcholine, alone or in combination, have all been implicated in the pathophysiology of depression. Since these neurotransmitters play an important role in neuroendocrine regulation, it is not surprising that they have been implicated in this dysregulation of the HPA axis present in depression. In examining their role in the neuroendocrine abnormality it is important to consider that the neurotransmitter control of ACTH has proven to be the most difficult to study of all the anterior pituitary hormone systems, and that there is considerable controversy regarding the specific effects of the various neurotransmitters on this system. According to the model most widely accepted (Martin et al., 1977; Reichlin, 1981), serotonin and actylcholine stimulate the secretion of ACTH and cortisol whereas norepinephrine appears to exert both inhibitory (mediated by $B$ adrenoreceptors) and excitatory (mediated by $\alpha$-adrenoreceptors) effects. Dopamine appears to play no major role in the regulation of the HPA axis,

Norepinephrine. The evidence supporting the involvement of a noradrenergic mechanism in the disinhibited HPA axis activity derives from the studies of Checkley (1979) and Sachar (1982). Checkley (1979) reported that the cortisol response to methamphetamine is attenuated in patients wi th endogenous depression compared to recovered patients, non-endogenous depressives, or patients with other psychiatric diagnoses. Sachar (1982) reports that the administration of dextroamphetamine inhibits the cortisol hypersecretion of depressed subjects and that their response differs from the response of normals in that there is no acute initial release. Both the inhibitory and excitatory effects of norepinephrine of the secretion of ACTH and cortisol have been implicated in explaining these results. Thus, the disinhibited cortisol secretion in depression is considered to be the result of decreased tonic inhibition due to decreased noradrenergic activity. This noradrenergic deficit is presumably reversed by dextroamphetamine which via release of norepinephrine inhibits cortisol secretion.

Alternatively it has been suggested that subsensitivity of postsynaptic $\alpha$-adrenergic receptors (presumably excitatory) is responsible for the disinhibited HPA axis activity and the at tenuated cortisol response to methamphetamine and dextroamphetamine. It is evident that improved understanding of the precise role of nopepinephrine in the regulation of the human HPA axis is necessary before any firm conclusions can be drawn regarding the role of norepinephrine in this neuroendocrine abnomality.

Serotonin. The serotonin antagonist, cyproheptadine, has been shown to suppress the ACTHcortisol disinhibition in Cushing 's disease (Krieger et al., 1975). Evidence, however, regarding the role of serotonin in the disinhibited HPA axis activity in depression is scanty. Carroll and co-workers (1980) reported a positive correlation between cerebrospinal fiuid levels of the serotonin metabolite 5-HIAA and post-dexamethasone plasma cortisol levels in patients with endogenous depression. Others (Asberg et al., 19BI) were unable to replicate this finding but did report a positive correlation between cerebrospinal fluid cortisol and 5-HIAA (Traskman et al., 1980). The latter, however, could be accounted for by the common correlation of both variables with body height. It is important at this point to emphasize that the classical biogenic amine hypothesis implicates a serotonin deficit in the pathophysiology of depression and that a positive correlation between measures of disinhibition of the HPA axis and increased serotonin turnover may be hard to reconclle with this hypothesis. clearly, more studies are needed before any conclusion can be drawn regarding the role of serotonin in this neuroendocrine abnormality.

Acetylcholine. In contrast to the indirect evidence in support of the role of norepinephrine and serotonin in this neuroendocrine abnormality, the role of cholinergic transmission in the cortisol escape from dexamethasone suppression has been studied directly by Carroll and co-workers (1980). Dexame thasone was given orally at 2300 hours to produce suppression of plasma cortisol levels to heal thy volunteers. The next day the actylcholinesterase inhibitor, physostigmine, was administered intravenously. Before the physostigmine began the subjects received methylscopolamine to block the peripheral effects of physostigmine. Control experiments were performed in which the stressful side effects of physostigmine were induced by oral ipecacuanha. Dexamethasone, as expected, induced persistent suppression of plasma cortisol. A clear rise in plasma cortisol was induced by physostigmine. Thus, nomal subjects manifested an escape from dexamethasone suppression associated with the administration of the acetylchollnesterase inhibitor physostigmine. Atropine, but not scopolamine, given before physostigmine prevented the escape. Cortisol levels did not increase in association with nausea induced by ipecacuanha. These results indicate that HPA escape from dexamethasone can be induced in normals by a muscarinic cholinergic mechanism and advocate an important role for actylcholine in the pathophysiology of the disinibited HPA axis activity 
in depression.

\section{B. Possible Role of an Impaired Opioid Inhibitory Mechanism}

There is considerable evidence in the experimental animal that the pituitary $\beta$-endorphin and ACTH-cortisol systems are anatomically and functionally related (Guillemin et al., 1977; Bloom et al., 1977; Mains et al., 1977; Vale et al., 1981). In addition to sharing a common precursor, cellular localization and secretory regulation, they have a camon clycocorticoid feedback mechanism since dexamethasone inhibits the secretion of both peptides (Guillemin et al., 1977). In man, the administration of dexamethasone suppresses ACTH and cortisol (Liddle et al., 1962; Berson and Yalow, 1968) while recent evidence suggests that it also suppresses $B$-endorphin (Mathews et al., 1982). Conversely there is evidence that opioids regulate the HPA axis since naloxone, an opioid antagonist, increases ACTH and cortisol (Volavka et al,, 1979; Morley et al., 1979; Grossman et a1., 1982). In the series of studies described below we have used a morphine infusion paradigm to provide evidence for an opioid inhibitory mechanism on the human ACTH-cortisol system. In addition, our results suggest that this mechanism is impaired in patients with endogenous depression.

Subjects and Methods. We have studied informed psychiatric inpatients ( $n=32$ ) and healthy yolunteers $(n=4)$ of either sex. All patients were drug-free for at least one week prior to the study. After an overnight fast, subjects remained supine from $7: 30 \mathrm{a} . \mathrm{m}$. until the completion of the study An indwelling catheter was inserted in the antecubital vein at 8:30 a.m. and kept open with a slow infusion of heparinized normal saline. Morphine sulfate, $5 \mathrm{mg}$, was injected intravenously at 9:30 a.m. Blood samples were drawn 15, immediately before, $30,60,90,120$, and 180 minutes after the morphine injection. In six of the patients and in the four healthy volunteers, the effect of morphi he was compared to a placebo injection (normal saline) 24 hours before or 48 hours after the morphine procedure. A Dexamethasone Suppression Test administered 48 to 96 hours after the morphine procedure was performed as standardized by Carroll $(1980)$. A plasma cortisol concentration greater than $5 \mu \mathrm{g} / \mathrm{dl}$ at 4:00 p.m. or 11:00 p.m. was considered abnormal (positive). Total plasma corticoids ("cortisol") were measured by the transcortin method of Murphy (1967). Diagnoses were made according to the Research Diagnostic Criteria (Spitzer et al., 1975) on the basis of all clinical information and a structured interview (Endicott and Spitzer, 1978). Diagnoses were made without access to the morphine infusion or the Dexamethasone Suppression Test results.

Results. Morphine suppressed cortisol secretion in all healthy volunteers. Figure 1 iliustrates the effect of morphine on plasma cortisol in a healthy male volunteer.
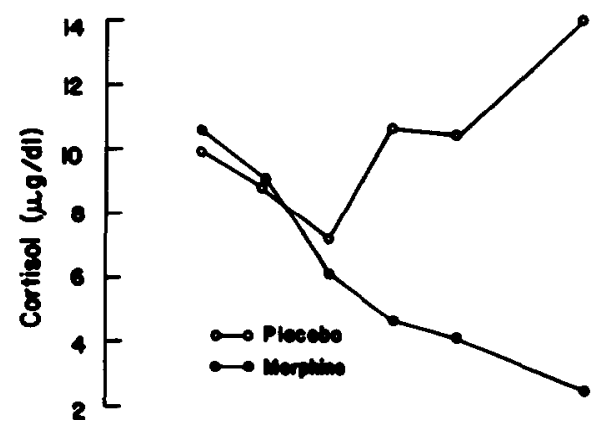

Figure 1. Effect of morphine $(5 \mathrm{mg})$ on plasma cortisol in a healthy volunteer

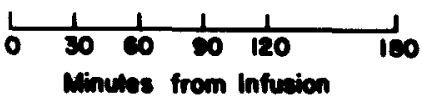

Cortisol levels decline progressively for the duration of the experiment after the morphine injection. In contrast, there is evidence for continuous secretory activity following the administration of placebo. Figure II illustrates the effect of morphine on plasma cortisol in a female patient with a diagnosis of major depressive disorder, endogenous subtype. 


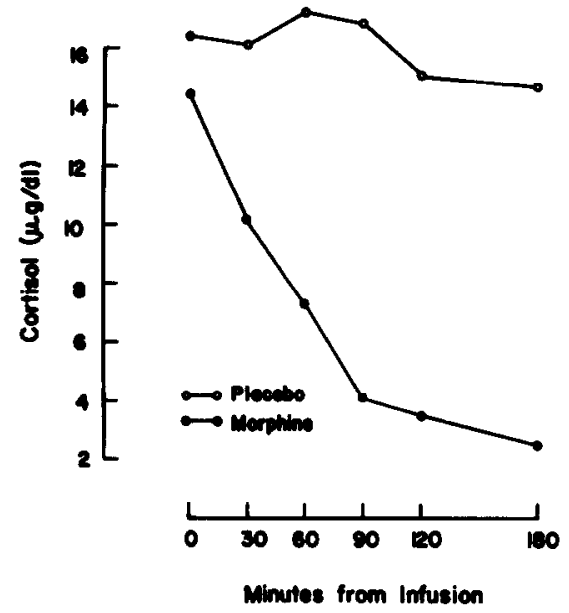

Figure 2. Effect of morphine $(5 \mathrm{mg})$ on plasma cortisol in a patient with major depression, endogenous subtype.

Baseline cortisol levels are, as anticipated, higher than those in the nomal volunteer and remain high after the administration of placebo. In sharp contrast, they decline progressively for the duration of the experiment in response to the morphine injection. This progressive decline, at a rate consistent with the half life of cortisol (Peterson and wyngaarden, 1956), has been observed in all healthy volunteers and psychiatric inpatients studied with the exception of approximately thirty percent of patients with major depressive disorder or schizoaffective disorder, depressed. In these patients, after the initial suppression of cortisol secretion there is an unambiguous upward swing of cortisol values indicating early resumption of cortisol secretion (escape).

The effect of morphine on cortisol secretion in one of these patients before and after a successful course of electroconvulsive treatment is depicted in Figure III.
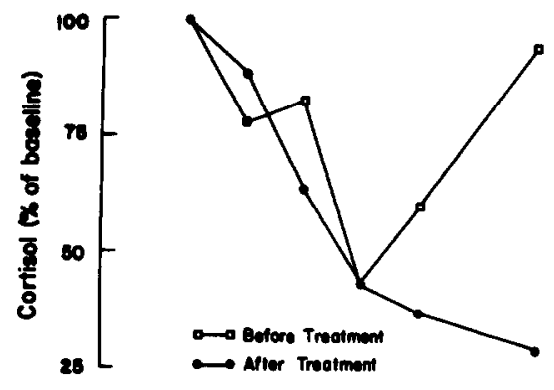

Figure 3 . Effect of morphine $(5 \mathrm{mg})$ on plasma cortisol in a patient with major depression, endogenous subtype before and after treatment.

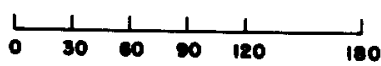

Minutes from Infusion

Before treatment, plasma cortisol levels started to rise at the 120 and 180 minutes blood samples indicating resumption of cortisol secretion whereas following treatment, when the patient was no longer depressed, cortisol values declined progressively for the duration of the experiment. Thus, it appears that this abnomality, i.e. early escape of cortisol from morphine suppression, is state dependent. 
We compared Dexamethasone Suppression Test results with the effect of morphine on plasma cortisol for the patients with major depression, endogenous subtype. We found an association between abnormal Dexamethasone Suppression Test results and early resumption of cortisol secretion following morphine administration. Within this diagnostic category cortisol escape from morphine suppression was $1 \mathrm{imited}$ to patients with abnormal Dexamethasone Suppression Test results.

Conclusions. The data presented here are consistent with the presence of an inhibitory opioid mechanism in the human HPA axis. Perhaps more important is the observation that the HPA axis appears to be insufficiently inhibited by this opioid mechanism in patients with major depression compared to normals or patients with other psychiatric diagnoses. Thus, the disinhibited activity of the HPA axis in patients with depression is resistant to both opioid (morphine) inhibition and glucocorticoid (dexamethasone) feedback. These observations suggest that the pathophysiology of this neuroendocrine disturbance is not limited to classical neurotransmitter-HPA axis interactions but that it also involves inhibitory opioid mechanisms.

\section{References}

ASBERG, M., AMINOFF, A.K., MARTENSON, B., TRASKMAN-BENDZ L., BERTILSSON, L. (1981). CSF monoaminemetabolites and the Dexamethasone Suppression Test - Independent biological correlates of depressive illness. Proc. 3rd World Congress of Biol Psychiat., Stockholm, Abstract $\mathrm{S} 11$.

BERSON, S.A. and YALOW, R.S. (1968). Radioimmunoassay of ACTH in plasma. J. Clin. Invest. 47: $-2725-2751$.

BLOOM F., BATTENBERG, E., ROSSIER, J., LING, N., LEPPALUOTO, J., VARGO, T.M., GUILLEMIN, R. (1977). Endorphins are located in the intermediate and anterior lobes of the pituitary gland, not in the neurohypophysis. Life Sci. 20: 43-48.

CARROLL, B.J., CURTIS, G.C., MENDELS, J. (1976a). Neuroendocrine regulation in depression. 1. Limbic system-adrenocortical dysfunction. Arch. Gen. Psychiat. 33: 1039-1:044.

CARROLL, B.J., CURTIS, G.C., MENDELS, J. (1976b). Neuroendocrine regulation of depression. 11. Discrimination of depressed from non-depressed patients. Arch. Gen. Psychiat. 33: $1051-1057$.

CARROLL, B.J., FEINBERG, M., GREDEN, J.F., TARIKA, J., ALBALA, A., HASKETT, R. F., JAMES, N. KRONFOL, Z., LOHR, N., DEVIGNE, J.P., YOUNG, E. (1981). A specific laboratory test for the diagnosis of melancholia. Standardization, validation, and clinical utility. Arch. Gen. Psychiat. 38: 15-22.

CARROLL, B.J., GREDEN, J.F., HASKETT, R., FE I VBERG, M., ALBALA, A.A., MART IN, F.I.R., RUBIN, R.T., HEATH, B., SHARP, P.T., MCLEOD, W.L., MCLEOD, M.F. (1980). Neurotransmitter studies of neuroendocpine patnology in depression. Acta Psychiat. Scan. Supp1. 280: 183-199.

CHECKLEY, S.A. (1979). Corticosteroid and growth hormone responses to methylamphetamine in depressive illness. Psychol. Med. g: 107-116.

COPPEN, A., ABOU-SALEH, M., MILLN, P., METCALFE, M., HARWOOD, J., BAIley, J. (1983). Dexamethasone Suppression Test in depression and other psychiatric illness, Brit. J. Psychiat. 142: $498-504$.

ENDICOTT, J. and SPITZER, R.L. (1978). A diagnostic interview. Arch. Gen. Psychiat. 35 : $837-844$.

GROSSMAN, A., GAILLARD, R.C., MCCARTNEY, P., REES, L.H., BESSER, G.M. (1982). Op iate modulation of the pituitary-adrenal axis: Effects of stress and circadian rhythm. Clin. Endo. 17: $279-286$.

GUILLEMIN, R., VARGO, R., ROSSIER, J., MINICK, S., LING, N., RIVIER, C., VALE, W., BLOOM, F. (1977). B-endorphin and adrenocorticotropin are secreted concomitantly by the pituitary 
9land. Science 197: 1307-1369.

KRIEGER, D.T., AMOROSA, L., LINICK, F. (1975). Cyproheptadine-induced remission of Cushing's disease. N. Eng. J. Med. 293: 893-896.

LIDDLE, G.W., ISLAND, D., MEADOR, C.K. (1962). Normal and abnormal regulation of corticotropin secretion in man. Recent Prog. Hor. Res. 18: 125-153.

MAINS, R.E., EIPPER, B.A., LING, N. (1977). Cormon precursor to corticotropins and endorphins. Proc. Nat. Aca. Sci. 74: 3014-3018.

MARTIN, J.B., REICHLIN S., BROWN, G.A. (1977). Clinical Neuroendocrinology. F.A. Davis, Phi ladelphia.

MATTHEWS, J., AKIL, H., GREDEN, J., WATSOH, S. (1982). Plasma measures of B-endorphin-like immunoreactivity in depressives and other psychiatric subjects. Life Sci. 31: 1867-1870.

MORLEY, J.E., BARANETSKY, N.G., WINGERT, T., CARLSON, H.E., HERSHMAN, J.M., MELMEd, S., LEVIN, S.R., JAMISON, K.R., WEITZMAN, R., CHANG, R.J., VARNER, A.A. (1979). Endocrine effects of naloxone-induced opiate receptor blockade." J. Clin. Endo. Metab. 50: 251-257.

MURPHY, B.E.P. (1967). Some studies of the protein binding of steroids and their application to the routine micro and ultramicro measurement of various steroids in body fluids by competitive protein-binding radioassay. J. Clin. Endo. 27: 973-990.

PETERSON, R.E., WYNGAARDEN, J.B. (1956). The miscible pool and turnover rate of hydrocortisone in man. J. Clin. Invest. 35: 552-561.

REICHLIN, S. (1981). Neuroendocrinology. In, Textbook of Endocrinology. R.H. Williams (ed.), W.B. Saunders, Phi ladelphia, pp. 589-645.

SACHAR, E.J. (1982). Endocrine abnormalities in depression. In, Handbook of Affective Disorders. E.S. Paykel (ed.), Churchill-Liningstone, Edinburgh, pp. 191-201.

SACHAR, E.J., HELLMAN, L., ROFFWARG, H., HALPERN., FUKUSHIMA, S., GALLAGHER, T. (1973). Disrupted 24-hour patterns of cortisol secretion in psychotic depression. Arch. Gen. Psychiat. 28: 29-44.

SPITZER, R.L., Endicott, J., Robins, E. (1975). Research Diagnostic Criteria, 2nd Edition. Biometrics Research, New York State Psychiatric Institute, New York.

TRASKMAN, L., TYBRING, G., ASBERG, M., BERTILSSON, L., LANTTO, 0., SCHALLING, D. (1980). Cortisol in CSF of depressed and suicidal patients. Arch. Gen. Psychiat. 37: 761-767.

VALE, W., SPIESS, J., RIVIER, C., RIVIER, J. (1981). Characterization of a 41-residue ovine hypothalamic peptide that stimulates secretion of corticotropin and $B$-endorphin. Science 213: $1394-1397$.

VOLAVKA, J., CHO, D., MALLYA, A., BAUMAN, J. (1979). Naloxane increases ACTH and cortisol levels in man. N. Eng. J. Med. 300: 1056-1057.

Inquirfes and reprint requests should be addressed to:

Dr. Athanasios P. Zis

Dept. of Psychistry

University of Michigan

Ann Arbor, Michigen 48109 